\title{
IDENTIFIKASI KEDALAMAN LAPISAN TANAH KERAS MENGGUNAKAN METODE GEOLISTRIK TAHANAN JENIS (STUDI KASUS: JALAN PERDANA KOTA PONTIANAK)
}

\author{
MASUDI $^{1}$, NURHASANAH ${ }^{2}$, MUHARDI $^{1, *}$ \\ ${ }^{1}$ Program Studi Geofisika, FMIPA, Universitas Tanjungpura \\ Jl. Prof. Dr. H. Hadari Nawawi, Bansir Laut, Kota Pontianak, Kalbar 78124 \\ ${ }^{2}$ Program Studi Fisika, FMIPA, Universitas Tanjungpura, \\ Jl. Prof. Dr. H. Hadari Nawawi, Bansir Laut, Kota Pontianak, Kalbar 78124
}

*email : muhardi@physics.untan.ac.id

\begin{abstract}
Abstrak. Identifikasi sebaran nilai tahanan jenis telah dilakukan di Jalan Perdana, Kelurahan Bansir Darat, Kecamatan Pontianak Tenggara, Kota Pontianak. Penelitian ini bertujuan untuk menentukan kedalaman lapisan tanah keras di area tanah gambut. Pengambilan data dilakukan menggunakan metode geolistrik tahanan jenis dengan konfigurasi Wenner-Schlumberger. Penelitian ini mengaplikasikan empat lintasan dengan panjang masing-masing $160 \mathrm{~m}$. Hasil penelitian menunjukkan bahwa sebaran nilai tahanan jenis pada lintasan 1 sebesar 1,89-120 $\Omega \mathrm{m}$, pada lintasan 2 sebesar $1,38-$ $140 \Omega \mathrm{m}$, pada lintasan 3 sebesar 2,39 - $132 \Omega \mathrm{m}$, dan pada lintasan 4 sebesar $1,15-101$ $\Omega \mathrm{m}$. Berdasarkan batas antara lapisan gambut dengan lapisan tanah keras, kedalaman lapisan tanah keras berada di bawah lapisan gambut yang dinterpretasi sebagai lapisan lempung berpasir dan diprediksi berada pada kedalaman 3,5-12,4 m.
\end{abstract}

Kata kunci: gambut, geolistrik, tahanan jenis, tanah keras

\begin{abstract}
Identifying the distribution of resistivity values has been conducted on Jalan Perdana, Bansir Darat Village, Southeast Pontianak District, Pontianak City. This study aims to determine the depth of the hard soil layer in the peatland area. The data was collected using the geoelectrical resistivity method of the Wenner-Schlumberger configuration. This study applied four lines have a length of $160 \mathrm{~m}$ each. The result showed that the distribution of resistivity values on line 1 about $1.89-120 \Omega \mathrm{m}$, in line 2 about 1.38 - $140 \Omega \mathrm{m}$, in line 3 about $2.39-132 \Omega \mathrm{m}$, and on line 4 about $1.15-101 \Omega \mathrm{m}$. Based on the boundary between the peat layer and the hard soil layer, the depth of the hard soil layer is under the peat layer, which is interpreted as a layer of clay and is predicted at a depth of about $3.5-12.4 \mathrm{~m}$.
\end{abstract}

Keywords: peat soil, geoelectric, resistivity, hard soil

\section{Pendahuluan}

Kota Pontianak mempunyai lahan tanah gambut yang cukup luas dan sebagian wilayahnya merupakan area pengembangan untuk pemukiman. Keberadaaan lapisan gambut diketahui terdapat di permukaan dengan ketebalan tertentu. Ketebalan tanah gambut bervariasi mulai dari $4 \mathrm{~m}$ [1] hingga 8,68 $\mathrm{m}$ [2] dan mencapai kedalaman $16 \mathrm{~m}[3]$. Persoalan yang muncul pada lahan gambut yang dianggap lunak adalah dalam hal perancangan pondasi. Dalam mengatasi persoalan tersebut, kedalaman pondasi ini minimal harus mencapai lapisan tanah keras[4]. Pondasi yang dibuat untuk konstruksi bangunan dengan beban yang ringan dapat mencapai lapisan lunak (lempung) dengan kedalaman 0.8-18.7 m, sedangkan bagi 
bangunan yang mempunyai beban berat harus dibangun pada batuan yang lebih keras yaitu batuan dasar (bedrock)[5]. Oleh karena itu, perancangan pondasi seharusnya memperhatikan kedalaman tanah keras agar dapat menopang beban bangunan dalam waktu yang lebih lama.

Penelitian ini dilakukan dengan tujuan untuk mengidentifikasi kedalaman lapisan tanah keras menggunakan metode geolistrik tahanan jenis (resistivitas) dengan konfigurasi Wenner Schlumberger[6]. Metode ini dianggap cukup efektif untuk mengidentifikasi litologi bawah permukaan[7], gerakan tanah[8] maupun keberadaan air tanah[9]. Kedalaman lapisan keras akan teridentifikasi dengan melihat batas lapisan yang akan ditunjukkan oleh adanya kontras nilai tahanan jenis dengan lapisan gambut yang berada di atasnya[1]. Informasi kedalaman tanah keras diharapkan dapat membantu untuk memperkirakan kedalaman pondasi agar dapat mencapai lapisan tanah keras tersebut karena dianggap lebih solid.

\section{Metode Penelitian}

Penelitian ini dilakukan di Jalan Perdana, Kelurahan Bansir Darat, Kecamatan Pontianak Tenggara, Kota Pontianak. Lintasan 1 berada pada koordinat 0003'58.69' S 109 $20^{\circ} 03.49^{\prime} \mathrm{E}-00^{\circ} 04^{\prime} 02.16^{\prime} \mathrm{S} 109^{\circ} 20^{\prime} 07.10^{\prime} \mathrm{E}$. Lintasan 2 berada pada koordinat $00^{\circ} 04^{\prime} 01.02^{\prime} \mathrm{S} 109^{\circ} 20^{\prime} 07.40^{\prime} \mathrm{E}-00^{\circ} 04^{\prime} 04.41^{\prime} \mathrm{S}$ $109^{\circ} 20^{\prime} 03.85^{\prime}$ E. Lintasan 3 berada pada koordinat $00^{\circ} 04^{\prime} 04.40^{\prime} \mathrm{S} 109^{\circ} 20^{\prime} 04.87^{\prime}$ E - 000.'01.09' S $109^{\circ} 20^{\circ} 01.42^{\prime}$ ' E. Lintasan 4 berada pada koordinat $00^{\circ} 03^{\prime}$ ' $58.69^{\prime}$

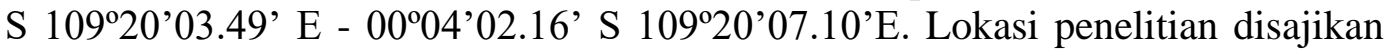
pada Gambar 1 berikut.

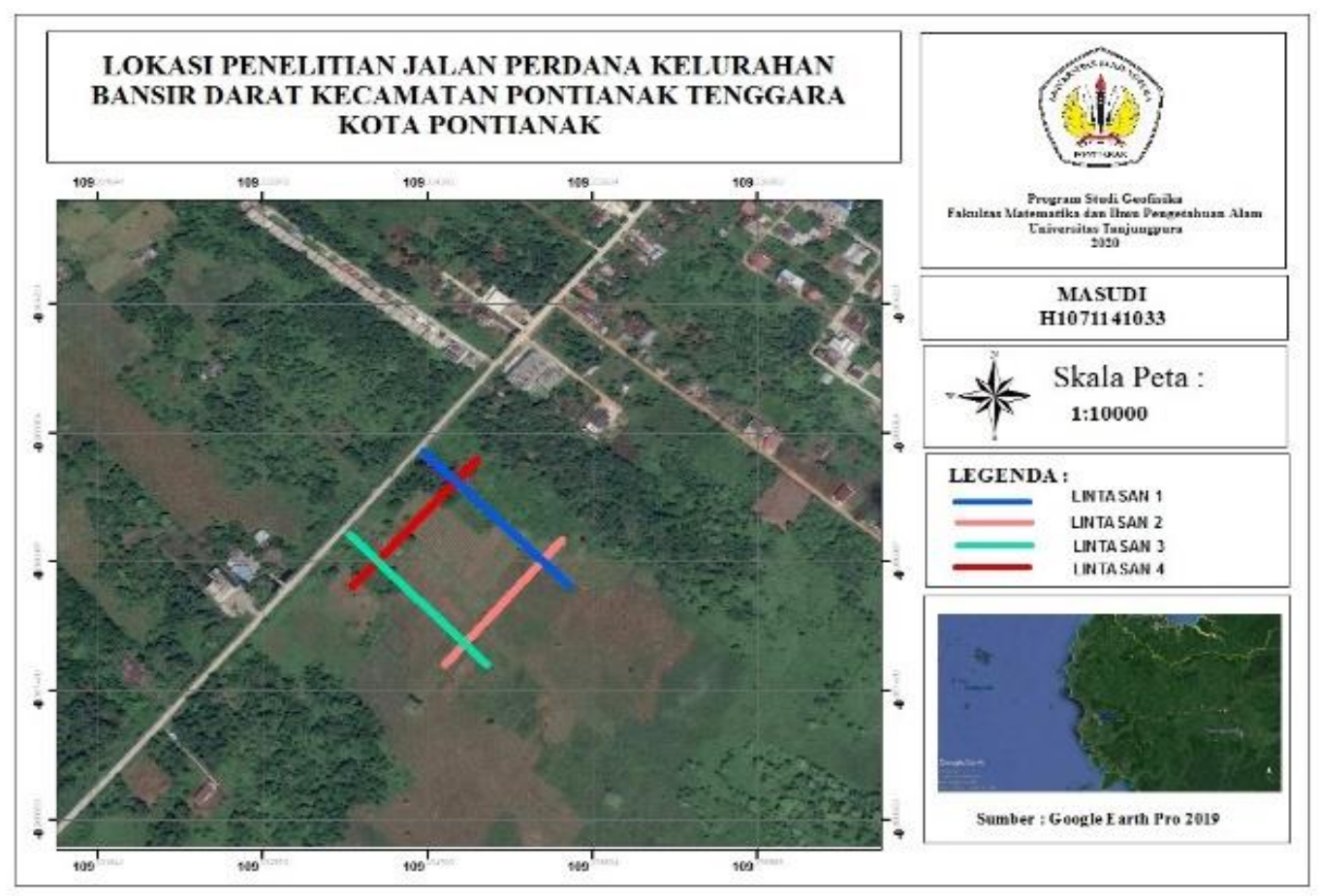

Gambar 1. Lokasi penelitian 
Akuisisi data dilakukan menggunakan alat geolistrik ARES (Automatic Resistivity System). Jumlah lintasan sebanyak 4 buah dengan panjang masing-masing $160 \mathrm{~m}$. Jarak antar elektroda sejauh $5 \mathrm{~m}$, sedangkan jarak antar lintasan yang sejajar sejauh $50 \mathrm{~m}$. Konfigurasi Wenner Schlumberger memiliki faktor rasio n (jumlahnya disesuaikan dengan kebutuhan) yang merupakan perbandingan jarak antara elektroda arus dan potensial, yaitu $\mathrm{C}_{1}-\mathrm{P}_{1}$ dan $\mathrm{C}_{2}-\mathrm{P}_{2}$, seperti yang disajikan pada Gambar 2. Jika $a$ adalah jarak antar elektroda potensial, maka akan diperoleh jarak antar elektroda arus sebesar 2na $+a$ [6].

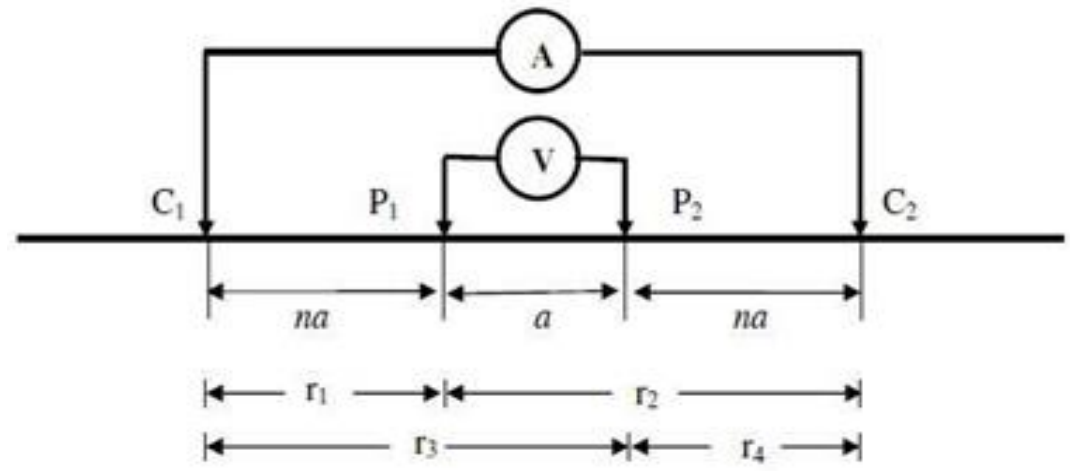

Gambar 2. Konfigurasi Wenner-Schlumberger[6]

Proses akuisisi data dimulai dengan melakukan injeksi arus listrik menggunakan elektroda arus di permukaan, sehingga menyebar ke bawah permukaan dan mengukur beda potensialnya menggunakan elektroda potensial[10]. Medium bawah permukaan diasumsikan sebagai lapisan yang homogen dan memiliki nilai tahanan jenis seragam, disebut sebagai tahanan jenis semu (Apparent Resistivity), yang dapat dirumuskan sebagai:

$$
\rho_{a}=K \frac{\Delta V}{I}
$$

Sehingga besar tahanan jenis semu adalah:

$$
\rho_{a}=2 \pi\left[\left(\frac{1}{r_{1}}-\frac{1}{r_{2}}-\frac{1}{r_{3}}+\frac{1}{r_{4}}\right)^{-1}\right] \frac{\Delta V}{I}
$$

Dengan:

$$
\begin{aligned}
\rho_{a .} & =\text { Tahanan jenis semu }(\Omega \mathrm{m}) \\
\Delta V & =\text { Beda potensial antara elektroda } \mathrm{P}_{1} \text { dan } \mathrm{P}_{2} \text { (Volt) } \\
I & =\text { Besarnya arus yang diinjeksikan melalui elektroda } \mathrm{C}_{1} \text { dan } \mathrm{C}_{2} \text { (Ampere) } \\
K & =\text { Faktor geometri }(\mathrm{m}) \\
r_{1} & =\text { Spasi antara elektroda arus } \mathrm{C}_{1} \text { dan elektroda potensial } \mathrm{P}_{1}(\mathrm{~m}) \\
r_{2} & =\text { Spasi antara elektroda arus } \mathrm{C}_{2} \text { dan elektroda potensial } \mathrm{P}_{1}(\mathrm{~m}) \\
r_{3} & =\text { Spasi antara elektroda arus } \mathrm{C}_{1} \text { dan elektroda potensial } \mathrm{P}_{2}(\mathrm{~m}) \\
r_{4} & =\text { Spasi antara elektroda arus } \mathrm{C}_{2} \text { dan elektroda potensial } \mathrm{P}_{2}(\mathrm{~m})
\end{aligned}
$$

Pengolahan data lapangan dilakukan untuk memperoleh nilai tahanan jenis semu. Proses inversi akan menghasilkan penampang tahanan jenis 2D yang sebenarnya dan kemudian dilakukan analisis yang disesuaikan dengan kondisi geologi setempat, 
penelitian sebelumnya di sekitar lokasi penelitian, dan nilai tahanan jenis dari tanah dan batuan pada tabel 1 .

Tabel 1. Tahanan jenis dari tanah dan batuan[11]

\begin{tabular}{ll}
\hline Material & Tahanan jenis $(\Omega \mathrm{m})$ \\
\hline Tanah Penutup & $250-1700$ \\
Lanau & $10-200$ \\
Batu Pasir & $1-6,4 \times 10^{8}$ \\
Lempung & $1-100$ \\
Lempung Pasiran & $80-1050$ \\
Pasir & $1-1000$ \\
Kerikil & $100-600$ \\
Alluvium & $10-800$ \\
\hline
\end{tabular}

\section{Hasil dan Pembahasan}

Hasil dari penampang tahanan jenis 2D di lokasi penelitian ditunjukkan pada Gambar 3. Batas antara lapisan tanah gambut dengan lapisan tanah keras ditunjukkan dengan garis hitam putus-putus. Gambar 3a menunjukkan sebaran nilai tahanan jenis pada lintasan 1 yaitu 1,89-120 $\Omega$ m. Berdasarkan batas antara lapisan tanah gambut dengan lapisan tanah keras, kedalaman lapisan keras tersebut diprediksi berada pada kedalaman 3,5-6 m. Gambar 3b menunjukkan sebaran nilai tahanan jenis pada lintasan 2 yaitu 1,38-140 $\Omega \mathrm{m}$. Berdasarkan batas antara lapisan tanah gambut dengan lapisan tanah keras, kedalaman lapisan keras tersebut diprediksi berada pada kedalaman 4,5-6,5 m.

Gambar 3c menunjukkan sebaran nilai tahanan jenis pada lintasan 3 yaitu 2,39$132 \Omega \mathrm{m}$. Berdasarkan batas antara lapisan tanah gambut dengan lapisan tanah keras, kedalaman lapisan keras tersebut diprediksi berada pada kedalaman $4-6 \mathrm{~m}$. Gambar 3d menunjukkan sebaran nilai tahanan jenis pada lintasan 4 yaitu 1,15$101 \Omega \mathrm{m}$. Berdasarkan batas antara lapisan tanah gambut dengan lapisan tanah keras, kedalaman lapisan keras tersebut diprediksi berada pada kedalaman $4-12,4 \mathrm{~m}$.

Lapisan tanah keras pada keempat lintasan di lokasi penelitian terdapat pada kedalamaan 3,5 - 12,4 m dengan nilai tahanan jenis lebih kecil jika dibandingkan dengan lapisan di atasnya. Lapisan tanah keras ini diinterpretasi sebagai lapisan lempung berpasir yang berada di bawah lapisan gambut. Lapisan gambut mempunyai nilai tahanan jenis yang relatif lebih besar karena mempunyai porositas yang lebih besar dan cenderung kurang solid. Sedangkan lapisan lempung berpasir mempunyai nilai tahanan jenis yang relatif lebih kecil dikarenakan mengandung mineral lempung yang dikenal memiliki tahanan jenis lebih kecil[12]. Sedangkan pada lintasan 3 terdapat anomali dengan nilai yang tahanan jenis yang relatif lebih besar yaitu di atas $100 \Omega \mathrm{m}$ pada kedalaman $15 \mathrm{~m}$ diduga batuan dasar yang diiinterpretasi sebagai batupasir. 


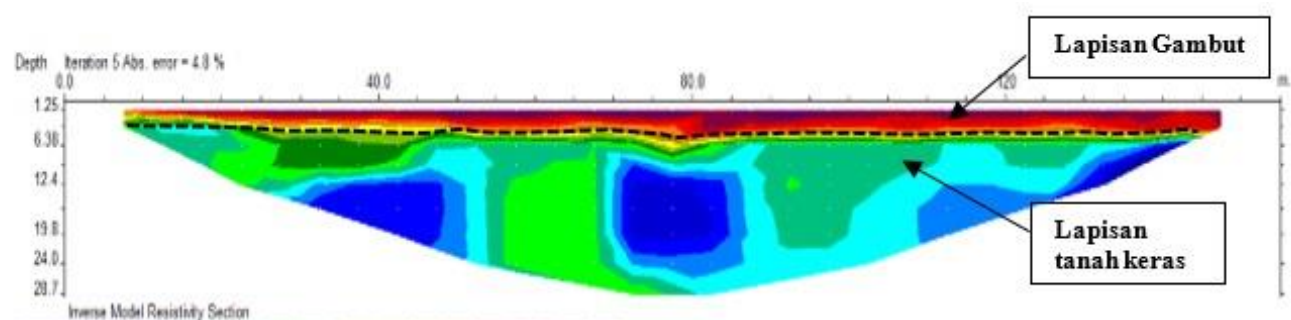

19.

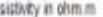

Unt swodude nocing 5 . 00 or

(a)

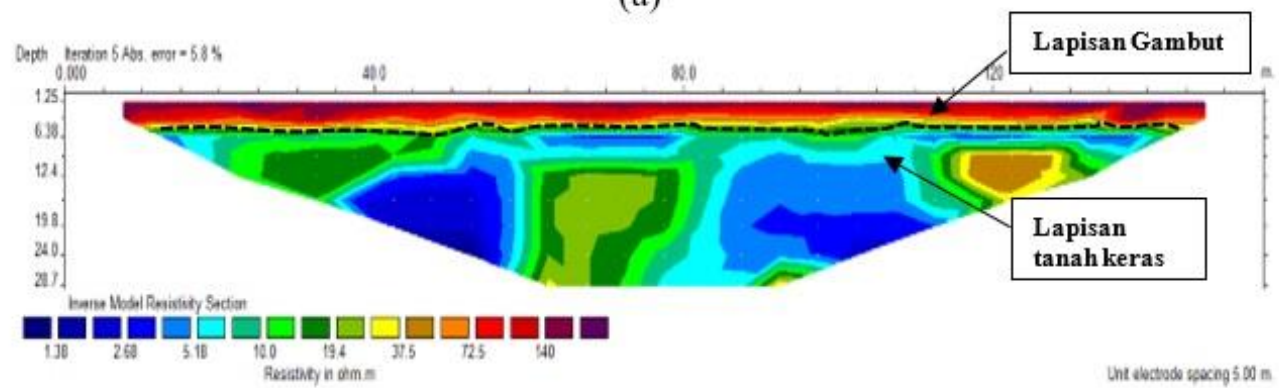

(b)

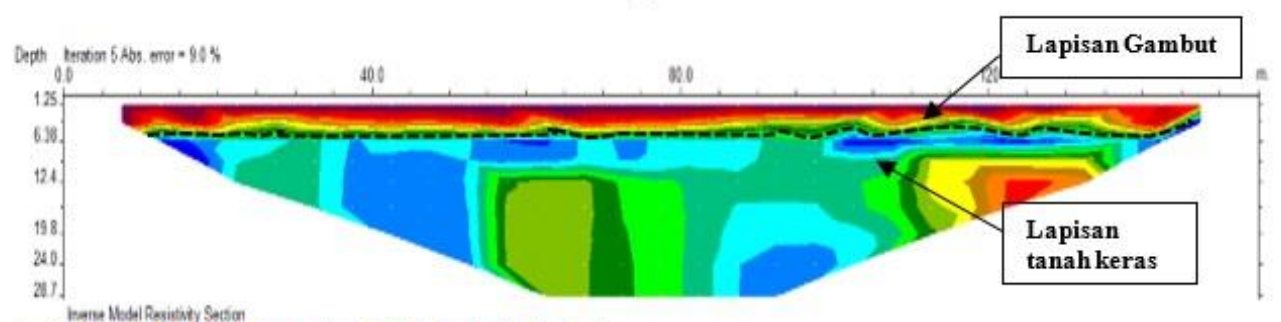

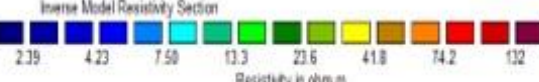

Unt wathod bereng 5 in m

(c)



(d)

Gambar 3. Penampang tahanan jenis (resistivitas) 2 D: (a) lintasan 1, (b) lintasan 2, (c) lintasan 3 , dan (d) lintasan 4

\section{Kesimpulan}

Berdasarkan hasil penelitian dapat disimpulkan bahwa sebaran nilai tahanan jenis

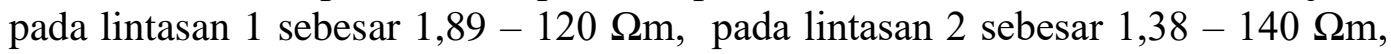
pada lintasan 3 sebesar 2,39-132 $\Omega \mathrm{m}$, dan pada lintasan 4 sebesar $1,15-101 \Omega \mathrm{m}$. 
Berdasarkan batas antara lapisan gambut dengan lapisan tanah keras, kedalaman lapisan tanah keras berada di bawah lapisan gambut yang dinterpretasi sebagai lapisan lempung berpasir dan diprediksi berada pada kedalaman 3,5 - 12,4 m. Dengan demikian perancangan pondasi harus memperhatikan kedalaman tanah keras tersebut agar pondasi bertumpu pada lapisan tanah yang lebih solid.

\section{Daftar Pustaka}

1. Muliadi, Zulfian, and Muhardi, "Identifikasi Ketebalan Tanah Gambut Berdasarkan Nilai Resistivitas 3D: Studi Kasus Daerah Tempat Pembuangan Akhir Batu Layang Kota Pontianak," Positron, vol. 9, no. 2, pp. 86-94, 2019.

2. F. Sirait and I. Andi, "Identifikasi struktur lapisan tanah gambut sebagai informasi awal rancang bangunan dengan metode geolistrik," vol. 3, no. 2, pp. 8-12, 2015.

3. L. Ramadhaningsih and J. Sampurno, "Identifikasi Struktur Lapisan Bawah Permukaan Lahan Gambut di Desa Arang Limbung Kecamatan Sungai Raya Kabupaten Kubu Raya dengan Metode Resistivitas Konfigurasi Dipole-Dipole," Phys. Commun., vol. 1, no. 2, pp. 29-35, 2017.

4. Syamsurizal, Cari, and Darsono, "Aplikasi Metoda Resistivitas untuk Identifikasi Litologi Batuan Sebagai Studi Awal Kegiatan Pembangunan Pondasi Gedung," Indones. J. Appl. Phys., vol. 3, no. 1, pp. 99-106, 2013.

5. R. Hutagalung and E. Bakker, "Identifikasi Jenis Batuan Menggunakan Metode Geolistrik Resistivitas Konfigurasi Schlumberger dalam Perencanaan Pondasi Bangunan di Terminal Ttransit Desa Passo," Pros. FMIPA Univ. Pattimura, pp. 159-167, 2013.

6. D. M. Loke, Electrical Imaging Surveys for Environmental and Engineering Studies. Geoelectrical.com, 2000.

7. Muhardi and Wahyudi, "Identifikasi Litologi Area Rawan Longsor di Desa Clapar-Banjarnegara Menggunakan Metode Geolistrik Resistivitas Konfigurasi Schlumberger," J. Fis., vol. 9, no. 2, pp. 52-59, 2019.

8. B. Santoso, Setianto, I. H. Mohammad, and Risdiana, "Investigasi Gerakan Tanah dan Akuifer menggunakan Metode Electrical Resistivity Tomography di Sekitar Lereng BGG-Jatinangor," J. Ilmu dan Inov. Fis., vol. 2, no. 1, pp. 45-52, 2018.

9. Muhardi, Faurizal, and Widodo, "Analisis Pengaruh Intrusi Air Laut terhadap Keberadaan Air Tanah di Desa Nusapati, Kabupaten Mempawah Menggunakan Metode Geolistrik Resistivitas,” Indones. J. Appl. Phys., vol. 10, no. 2, pp. 89-96, 2020.

10. M. E. Everett, Near-Surface Applied Geophysics. New York: Cambridge University Press, 2013.

11. W. M. Telford, L. P. Geldart, and R. E. Sheriff, Applied Geophysics, Second Edi. New York: Cambridge University Press, 1990.

12. A. Kurniawan, "Sifat Resistivitas Rendah Mineral Lempung," Masy. Ilmu Bumi Indones., vol. 1, no. 2, pp. 1-9, 2014. 